Abstract 45 Table 1 Showing baseline characteristics and source of patient referrals from the turned down cohort

\begin{tabular}{|c|c|}
\hline Characteristics & $\mathrm{n}=235(\%)$ \\
\hline Median Age (IQR) & $69(24,94)$ \\
\hline Male gender & $172(73)$ \\
\hline \multicolumn{2}{|l|}{ Referral source } \\
\hline Northern Ireland Ambulance Service (NIAS) & $146(62)$ \\
\hline Emergency Department & $68(29)$ \\
\hline In-patient & $21(9)$ \\
\hline \multicolumn{2}{|l|}{ Was the referral appropriately rejected? } \\
\hline No & $9(4)$ \\
\hline Yes & $226(96)$ \\
\hline $\mathrm{pPCl}$ done? & $224(95)$ \\
\hline No & $11(5)$ \\
\hline \multicolumn{2}{|l|}{ Yes } \\
\hline \multicolumn{2}{|l|}{ Patients re-referred for $\mathrm{PCI}$ ? } \\
\hline No & $182(77)$ \\
\hline Yes & $53(23)$ \\
\hline \multicolumn{2}{|l|}{ Number of patients who had intervention } \\
\hline $\mathrm{PCl}$ & $35(15)$ \\
\hline CABG & $2(1)$ \\
\hline Diabetes mellitus & $70(30)$ \\
\hline Hypertension & $133(57)$ \\
\hline Dyslipidaemia & $184(78)$ \\
\hline \multicolumn{2}{|l|}{ Smoking history } \\
\hline Never smoked & $73(31)$ \\
\hline Current smoker & $48(20)$ \\
\hline Ex-smoker & $86(37)$ \\
\hline Unknown & $28(12)$ \\
\hline Chronic kidney disease & $68(29)$ \\
\hline Prior ischaemic heart disease & $100(43)$ \\
\hline BMI (mean, SD) & $24.05 \pm 12.02 \mathrm{~kg} / \mathrm{m}^{2}$ \\
\hline Troponin T (median, IQR) & $35(0,10,000) \mathrm{ng} / \mathrm{L}$ \\
\hline Clinical COVID-19 diagnosis & $16(7)$ \\
\hline Covid-19 swab positive & $4(2)$ \\
\hline Mortality & $38(16)$ \\
\hline - Days before death (median, 1QR) & $10(0,157)$ \\
\hline
\end{tabular}

Abstract 45 Table 2 Showing the final diagnosis of patients and the proportion of patients who died during study period from the turned down cohort

\begin{tabular}{lll}
\hline Final Diagnosis & Number (\%) & Mortality (\%) \\
\hline STEMI & $12(5)$ & $2(5)$ \\
Late STEMI & $8(3)$ & $5(13)$ \\
NSTEMI & $41(17)$ & $4(11)$ \\
Unstable angina & $3(1)$ & 0 \\
Spontaneous coronary artery dissection & $1(0.5)$ & 0 \\
Angina & $13(6)$ & 0 \\
Takotsubo syndrome & $6(3)$ & $2(5)$ \\
Pericarditis & $3(1)$ & 0 \\
Myocarditis & $1(0.5)$ & 0 \\
Congestive cardiac failure & $10(4)$ & $3(8)$ \\
Arrhythmia & $29(12)$ & $5(13)$ \\
Non-cardiac chest pain & $25(11)$ & 0 \\
Miscellaneous & $67(29)$ & $12(32)$ \\
COVID & $16(7)$ & $5(13)$ \\
TOTAL & 235 & 38 \\
\hline
\end{tabular}

database and call log sheets. Supplementary clinical data was collected using the Northern Ireland Electronic Care Record (NIECR). A turn down was deemed inappropriate if retrospective review of history and ECG demonstrated that the pPCI pathway entry criteria had been met. The number of pPCIs performed was compared with the same time period in 2019. Results A total of 388 referrals were made to the Belfast pPCI service over a period of 78 days [figure 1]. 19 invalid referrals were excluded, 15 with missing ECGs and 4 duplicate referrals. 134 patients were accepted for pPCI and 235 referrals were turned down, of which 9 (4\%) were deemed inappropriate. No referrals were turned down due to COVID-19. Of the inappropriate turned downs 6 were re-referred and had pPCI to a culprit coronary artery, 2 had routine PCI to a culprit coronary artery and 1 had Takotsubo syndrome. From the accepted cohort, $114(85 \%)$ had pPCI to a culprit coronary artery and $20(15 \%)$ had no intervention (3 Takotsubo syndrome, 1 coronary spasm, 4 pericarditis, 3 chronic total occlusion of coronary artery, 8 non-obstructive coronary artery disease and 1 stroke). In the appropriately turned down cohort, the final diagnosis was cardiac in 127 (53\%) patients, non-cardiac chest pain in $25(11 \%)$, miscellaneous in 67 (29\%) and COVID-19 in 16 (7\%) [table 2]. One-year mortality rate of the turned down cohort was $16 \%$ (38/235) of which $55 \%(21 / 38)$ was in the cohort with a final cardiac diagnosis, $13 \%(5 / 38)$ was due to COVID-19 and the remaining $32 \%(12 / 38)$ from the miscellaneous cohort [table 1 and 2]. In 2020 there was a $29 \%$ (130 vs 182$)$ reduction in the number of pPCIs performed in the 3 months from March to May in comparison with the previous year [figure 2].

Conclusions During the first wave of COVID-19 there was a significant reduction in the number of pPCIs performed. This was not due to an increase in inappropriate turn down of referrals. No patient was turned down because of COVID-19. Of the turned down patients the majority (53\%) had a final cardiac diagnosis. One year mortality in this group was significant.

\section{ACUTE MYOCARDIAL INFARCTION AND LIPID LEVELS PRE AND POST PRIMARY \pm SECONDARY TREATMENT: A ONE-YEAR LIPID OUTCOME STUDY}

${ }^{1} \mathrm{M}$ Saad Ahmed, '1 Coburn, ${ }^{1} \mathrm{P}$ Collins, ${ }^{2}$ I Menown. ${ }^{1}$ Royal Victoria Hospital, Belfast Trust, NHS, UK; ${ }^{2}$ Craigavon Area Hospital, Southern Trust, NHS, UK

\subsection{6/heartjnl-2021-ICS.46}

ESC guidelines recommend a target LDL cholesterol (LDL-C) of $<1.8 \mathrm{mmol} / \mathrm{l}$ following myocardial infarction (MI). Early assessment of lipids post $\mathrm{MI}$ is confounded by acute phase response requiring convalescent re-testing to guide need or otherwise for up-titration \pm additional treatment.

Methods We studied consecutive patients admitted with acute myocardial infarction over one year (April 2016 - April 2017). Baseline diagnosis, cardiovascular (CV) risk factors, CV history, lipid treatment before admission (if any), lipid levels pre or within 24 hours of admission, lipid treatment on discharge, lipid levels at $>3$ months follow up, and changes to lipid treatment during follow up were recorded.

Results Of 293 patients admitted with acute MI, 108 (36.8\%) had ST elevation MI and 185(63.2\%) non-ST elevation MI or unstable angina. Gender split was approximately 2:1 male: female. Baseline CV risk factors included family history 63 
(21.5\%), smoking [current 83(28.3\%); ex 103(35.2\%)], hypertension 155(52.5\%), hyperlipidaemia 207(70.6\%), or diabetes 67(22.3\%). Past CV history included prior MI 57(19.4\%), prior revascularisation 53(18.1\%), TIA/stroke 22(7.5\%) or peripheral arterial disease 33(11.3\%). Lipid levels pre or within 24 hours of admission were available in 248(84\%) patients. For those already on lipid treatment 144 (49.1\%) and an admission LDL was available, mean LDL-C was $2.15 \mathrm{mmol} / 1$; for those not on treatment, mean LDL-C was $3.27 \mathrm{mmol} / \mathrm{l}$. At discharge, 269(91.8\%) patients were receiving lipid lowering therapy [atorvastatin 242 (90\%); rosuvastatin $15(5.6 \%)$; simvastatin $8(2.97 \%)$; pravastatin $2(0.01 \%)$; and 1 person on ezetimibe]. Follow up lipids at $>3$ months were available in $166(56.7 \%)$ in whom mean LDL-C was $1.87 \mathrm{mmol} / \mathrm{l}$ and $82(49.4 \%)$ met the ESC target of $<1.8 \mathrm{mmol} /$ 1. For those not at target, adjustment in lipid treatment was undertaken in 11(10\%) [statin increase/switch in all cases]. Follow up lipids beyond 6 months were obtained in 190 (64.8\% of lipids) of those $110(57 \%)$ achieved and LDL-C of $<1.8 \mathrm{mmol} / \mathrm{L} ; 15(7.8 \%)$ had LDL-C of $3 \mathrm{mmol} / \mathrm{L}$.

Conclusion In an unselected consecutive acute MI population, despite use of contemporary intensive statin therapy in $>90 \%$ of patients, LDL-C levels remain suboptimal in 92(27\%) of those taking statins. Lipid follow up is a key element of follow up with need for adjustment in statin \pm additional treatment required in approximately $30 \%$ of patients.

\section{META-ANALYSIS OF RANDOMISED CONTROLLED TRIALS INVESTIGATING THE IMPACT OF COLCHICINE ON MAJOR ADVERSE CARDIOVASCULAR EVENTS IN ACUTE CORONARY SYNDROME}

${ }^{1} \mathrm{~N}$ Blake, ${ }^{1} \mathrm{~A}$ Alonso, ${ }^{1,2} \mathrm{H}$ Rai, ${ }^{1,2} \mathrm{R}$ Colleran, ${ }^{1,2} \mathrm{D}$ Giacoppo, ${ }^{1,2} \mathrm{G}$ Blake, ${ }^{1,2} \mathrm{RA}$ Byrne. ${ }^{1}$ Mater Private Hospital, Cardiovascular Research Institute (CVRI) Dublin, Ireland; ${ }^{2} R C S I$ School of Pharmacy and Biomolecular Sciences, Royal College of Surgeons, Dublin, Ireland

10.1136/heartjnl-2021-ICS.47

Introduction Colchicine has been shown to reduce inflammation and has a potential to stabilise atherosclerotic plaques. Clinical studies have suggested a role for colchicine in reducing adverse cardiovascular events in patients with coronary artery disease. The aim of the present meta-analysis was to investigate the effect of colchicine on outcomes following coronary intervention among patients presenting with acute coronary syndrome (ACS).

Methods We searched for randomised controlled trials (RCTs) comparing colchicine to placebo in patients with ACS undergoing coronary intervention using the initial MESH terms 'colchicine' and 'cardiovascular system'. Eligible RCTs published up to November 2020 were included. We also searched presentations from the proceedings of relevant international scientific meetings. The primary endpoint was major adverse cardiovascular events (MACE). Study level odds ratios (ORs) and $95 \%$ confidence intervals (CI) of MACE were pooled using the Mantel-Haenszel method and random effects model. Forest plots were generated using Review Manager (RevMan) 5.4 software.

Results Our initial search identified 1,049 articles for potential inclusion. Of these studies, 4 RCTs were found to be eligible: COPS, COLCHICINE-PCI, COLCOT time-to-Initiation (TTI) 0-3 days and PODCAST-PCI. Overall a total of 2,709 patients were randomly allocated to treatment with either colchicine $(n=1,367)$ or placebo $(n=1,342)$. Patients received colchicine either prior to angiography or within 3 days post-procedure. Follow up duration ranged from 30 days to 3 years. Mean age of the whole analysed cohort was $60.3 \pm 10.5$ years; $73 \%$ were male; $51 \%$ had a history of hypertension, $26 \%$ had diabetes mellitus, 38\% were current smokers. There were 89 events in the colchicine group as opposed to 133 events in the placebo group. The risk of MACE was lower in patients treated with colchicine as compared with placebo (OR 0.63, $95 \%$ CI $0.48-0.84, \mathrm{p}=0.001$ ) (see figure 1). Heterogeneity across trials was not detectable $\left(\mathrm{I}^{2}=0\right)$.

Conclusions The results of our meta-analysis suggest that among patients presenting with acute coronary syndrome undergoing coronary intervention, treatment with colchicine instead of placebo reduces the risk of MACE. Further investigations in larger cohorts are warranted to test this effect.

\section{8 IDENTIFICATION OF NOVEL PROTEIN BIOMARKERS FOR ATRIAL FIBRILLATION}

${ }^{1} \mathrm{C}$ Tonry, ${ }^{1} \mathrm{~A}$ Russell-Hallinan, ${ }^{2} \mathrm{P}$ Collier, ${ }^{3,4} \mathrm{~K}$ McDonald, ${ }^{3,4} \mathrm{M}$ Ledwidge, ${ }^{5} \mathrm{~B}$ Collins, ${ }^{1,3,4} \mathrm{CJ}$ Watson. ${ }^{1}$ Wellcome-Wolfoson Institute of Experimental Medicine, Queens University Belfast, UK; ${ }^{2}$ Department of Cardiovascular Medicine, Cleveland Clinic, OH; ${ }^{3}$ STOP-HF Unit, St. Vincent's University Healthcare Group, Dublin, Ireland; ${ }^{4}$ Heartbeat Trust, Dublin, Ireland; ${ }^{5}$ School of Biological Sciences, Queens University Belfast

10.1136/heartjnl-2021-ICS.48

NOT AVAILABLE FOR PUBLICATION

\section{DYSLIPIDAEMIA MANAGEMENT IN THE CARDIAC REHABILITATION CLINIC OF A TERTIARY REFERRAL CENTRE; ANALYSIS OF THE IMPACT OF NEW ESC GUIDANCE ON LDL-C TARGET ACHIEVEMENT}

C McCaughey, D Ranganathan, M Kerins, G Murphy, R Murphy. St James's Hospital Dublin, Ireland

\subsection{6/heartjnl-2021-ICS.49}

Background Cardiac rehabilitation (CR) programs provide an opportunity to measure low density lipoprotein cholesterol (LDL-C) levels and optimise lipid lowering therapy (LLT) accordingly. New ESC guidelines released in August 2019

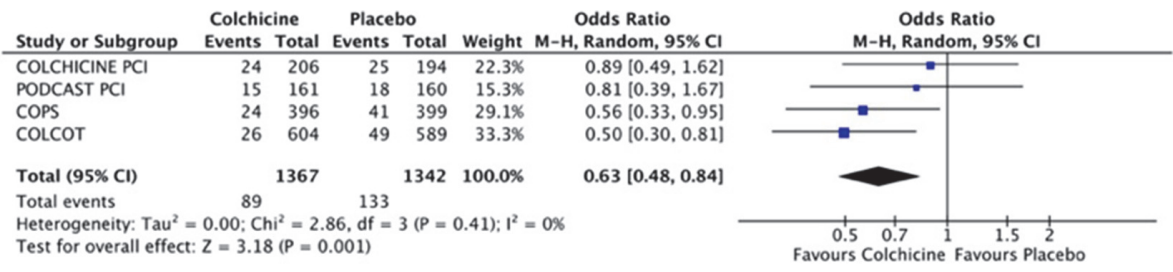

Abstract 47 Figure 1 Risk of MACE in patients treated with colchicine as compared with placebo 